\title{
The potential of regional myocardial blood flow measurement with SPECT
}

\author{
Matthieu Pelletier-Galarneau, MD, MSc, ${ }^{\text {a,b }}$ and Terrence D. Ruddy, $M^{c}$ \\ a Department of Medical Imaging, Montreal Heart Institute, Montreal, QC, Canada \\ b Gordon Center for Medical Imaging, Massachusetts General Hospital, Harvard Medical School, \\ Boston, MA \\ c Division of Cardiology, University of Ottawa Heart Institute, Ottawa, ON, Canada
}

Received Apr 11, 2019; accepted Apr 11, 2019

doi: $10.1007 /$ s12350-019-01727-7

\section{See related article, pp. 249-259}

Myocardial perfusion imaging (MPI) with SPECT has been widely used for the diagnosis and risk stratification of patients with coronary artery disease (CAD) for over 30 years. Its utilization is supported by numerous large studies validating its diagnostic accuracy and prognostic value. ${ }^{1}$ However, SPECT MPI is limited as a relative perfusion imaging technique and this has been further emphasized by recent advances in PET MPI and absolute myocardial blood flow (MBF) quantification. $^{2}$ Relative imaging relies on the assumption that areas with the highest tracer uptake are perfused by non-obstructed coronary arteries and are normal. $^{3}$ Thus, relative MPI can be associated with underestimation of CAD severity and extent, especially in cases of multivessel disease. ${ }^{4}$ In that context, MBF quantification could enhance the diagnostic performance of SPECT MPI, as well as to provide incremental prognostic value over relative perfusion imaging alone.

Assessment of MBF with PET has been validated with different tracers and is currently routinely used in the clinical setting with various commercially available software programs. ${ }^{5}$ Accurate $\mathrm{MBF}$ quantification requires a dynamic acquisition to assess the tracer firstpass circulation in the myocardium, which is readily possible with current PET systems. Unfortunately, PET cameras are not widely available and SPECT remains

Reprint requests: Terrence D. Ruddy, MD, Division of Cardiology, University of Ottawa Heart Institute, 40 Ruskin Street, Ottawa, ON, K1Y 4W7, Canada; TRuddy@ottawaheart.ca

J Nucl Cardiol 2021;28:260-2.

$1071-3581 / \$ 34.00$

Copyright (C) 2019 American Society of Nuclear Cardiology. the work-horse of nuclear cardiology. Although feasible, ${ }^{6}$ quantification of MBF is suboptimal with conventional NaI SPECT systems as they have low count sensitivity and poor temporal resolution. The advent of new SPECT systems with solid state cadmium-zinc-telluride (CZT) detectors and a non-rotating gantry design such as the Discovery NM 530c/570c (GE Healthcare) and the D-SPECT Cardio (Spectrum Dynamics) systems can circumvent many of the conventional anger camera limitations, with higher sensitivity and allowing improved temporal and spatial resolution. The first preclinical validation of MBF assessment with a CZT camera was performed in pigs and compared to microspheres. ${ }^{7}$ The authors showed that MBF quantification with both ${ }^{99 \mathrm{~m}} \mathrm{Tc}$-labeled tetrofosmin and sestamibi tracers and ${ }^{201} \mathrm{Tl}$ was possible. As well, several studies have shown the feasibility of MBF quantification with SPECT in humans. ${ }^{6,8-12}$

In this issue of the Journal of Nuclear Cardiology ${ }^{\circledR}$, Zavadovsky et al. ${ }^{13}$ report the diagnostic accuracy of regional MBF, coronary flow reserve (CFR), and flow difference (Stress MBF-Rest MBF) assessed with a CZT camera for detection of obstructive CAD identified with invasive coronary angiography and fractional flow reserve (FFR). Twenty-three patients underwent same day rest-stress dynamic imaging with ${ }^{99 \mathrm{~m}} \mathrm{Tc}$-sestamibi on a Discovery NM/CT 570c camera with stress injection $\left(9 \mathrm{MBq} \cdot \mathrm{kg}^{-1}\right)$ performed 45 minutes after rest injection $\left(3 \mathrm{MBq} \cdot \mathrm{kg}^{-1}\right)$, followed by coronary angiography within 7 days. Importantly, FFR was measured in all stenotic arteries when technically possible, allowing combined anatomical (\% stenosis) and functional (FFR) per-vessel analysis. Global and regional MBF was quantified using a net retention model without correction for extraction fraction. ${ }^{14}$ The authors report significant correlations between regional MBF $(r=0.63)$, CFR $(r=0.66)$, and flow difference $(r=0.73)$ vs FFR values. 
In regions with CFR below 1.48, FFR was significantly reduced in $90 \%$ of cases and in regions with preserved CFR, FFR was normal in $78 \%$ of cases. Of interest, these flow parameters better predicted the presence of impaired FFR compared to conventional semi-quantitative perfusion parameters derived from relative perfusion images. These results support those of Miyagawa et al. ${ }^{15}$ who showed a significant correlation $(r=0.62)$ between FFR and regional CFR index in a larger population.

The average global rest $(0.36$, range 0.33 $\left.0.54 \mathrm{~mL}^{-1} \cdot \mathrm{minute}^{-1} \cdot \mathrm{g}^{-1}\right)$ and stress $\operatorname{MBF}(0.67$, range $\left.0.55-0.81 \mathrm{~mL}^{-1} \cdot \mathrm{minute}^{-1} \cdot \mathrm{g}^{-1}\right)$ values reported are strikingly decreased compared to those reported by other studies using either PET or SPECT (Figure 1), and well below the physiological range. The authors attribute those low flow values to the tracer kinetic properties of ${ }^{99 \mathrm{~m}}$ Tc-sestamibi. The extraction fraction of sestamibi decreases with increasing $\mathrm{MBF} .{ }^{14}$ Appropriate extraction fraction correction in the model will permit accurate measurement of $\mathrm{MBF}$ with more physiologic values, ${ }^{7,9,12}$ particularly for stress MBF. However, the lack of extraction fraction correction does not explain the low rest flows which may be due to inaccurate scaling of the integrated myocardial uptake and the arterial input data. Notably, the CFR measurements are more reasonable which may reflect cancelation of this scaling factor when using the ratio of stress and rest flows.

Despite this limitation of low rest and stress $\mathrm{MBF}$ values, this study presents interesting results that are a welcome addition to the body of literature demonstrating the feasibility and possible role of $\mathrm{MBF}$ quantification with SPECT. One of the most remarkable findings of this study is that among ten patients with normal relative perfusion images (sum rest score and sum stress score $\leq 3), 6(60 \%)$ patients had significant

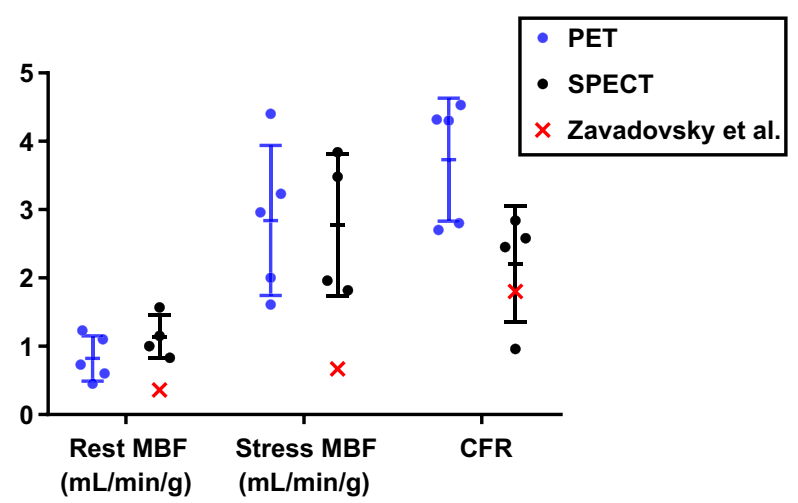

Figure 1. Representative samples of rest MBF, stress MBF, and CFR for PET (blue) ${ }^{16-20}$ and SPECT (black) ${ }^{6,9-11}$ in various populations with and without $\mathrm{CAD}$. The rest and stress MBF obtained by Zavadovsky et al. (red) appear lower compared to other studies especially for stress MBF.
CAD on angiography including multivessel disease in 3 $(30 \%)$ of subjects. In these six patients, mean global stress MBF was significantly lower than patients without significant CAD. Thus, measurement of global stress MBF could improve sensitivity of SPECT MPI, especially in the context of multivessel CAD.

Prior to wider clinical implementation, standardization of MBF quantification is desirable for clinical care and multicenter studies. While some studies use extraction fraction parameters of other tracers such as ammonia to calculate index of $\mathrm{MBF}^{8}$, others rely on ratios of $\mathrm{K} 1$ values avoiding extraction fraction correction. ${ }^{15}$ SPECT MBF measurements with extraction fraction correction correlate well with PET measurements using a 1-tissue-compartment model $^{12}$ and a retention model, ${ }^{9}$ suggesting that this approach with extraction fraction correction is optimal. Multicenter studies assessing the diagnostic performance and the prognostic utility of SPECT MBF are also necessary to determine its incremental value relative to relative perfusion imaging. Supplemental technical and professional reimbursement will be necessary to offset the increased time required for acquisition, processing, and interpretation and much easier to justify with additional clinical value. SPECT measurement of MBF has much potential which now needs to be realized.

\section{Disclosure}

Dr. Terrence D. Ruddy has received research grant support from GE Healthcare and Advanced Accelerator Applications Inc. Dr. Matthieu Pelletier-Galarneau has nothing to disclose.

\section{References}

1. Jaarsma C, Leiner T, Bekkers SC, et al. Diagnostic performance of noninvasive myocardial perfusion imaging using single-photon emission computed tomography, cardiac magnetic resonance, and positron emission tomography imaging for the detection of obstructive coronary artery disease: A meta-analysis. J Am Coll Cardiol 2012;59:1719-28. https://doi.org/10.1016/j.jacc.2011.12. 040 .

2. Murthy VL, Bateman TM, Beanlands RS, et al. Clinical quantification of myocardial blood flow using PET: Joint position paper of the SNMMI Cardiovascular Council and the ASNC. J Nucl Med 2018;59:273-93. https://doi.org/10.2967/jnumed.117.201368.

3. Alenazy AB, Wells RG, Ruddy TD. New solid state cadmiumzinc-telluride technology for cardiac single photon emission computed tomographic myocardial perfusion imaging. Expert Rev Med Devices 2017;14:213-22. https://doi.org/10.1080/17434440. 2017.1296763.

4. Parkash R, deKemp RA, Ruddy TD, et al. Potential utility of rubidium 82 PET quantification in patients with 3-vessel coronary artery disease. J Nucl Cardiol 2004;11:440-9. https://doi.org/10. 1016/j.nuclcard.2004.04.005. 
5. Pelletier-Galarneau M, Martineau P, El Fakhri G. Quantification of PET myocardial blood flow. Curr Cardiol Rep 2019;21:11. h ttps://doi.org/10.1007/s11886-019-1096-x.

6. Klein R, Hung G-U, Wu T-C, et al. Feasibility and operator variability of myocardial blood flow and reserve measurements with ${ }^{99} \mathrm{mTc}$-sestamibi quantitative dynamic SPECT/CT imaging. J Nucl Cardiol 2014;21:1075-88. https://doi.org/10.1007/s12350-01 4-9971-8.

7. Wells RG, Timmins R, Klein R, et al. Dynamic SPECT measurement of absolute myocardial blood flow in a porcine model. J Nucl Med 2014;55:1685-91. https://doi.org/10.2967/jnumed.114. 139782.

8. Nkoulou R, Fuchs TA, Pazhenkottil AP, et al. Absolute myocardial blood flow and flow reserve assessed by gated SPECT with cadmium-zinc-telluride detectors using 99mTc-tetrofosmin: Head-to-head comparison with $13 \mathrm{~N}$-ammonia PET. J Nucl Med 2016;57:1887-92. https://doi.org/10.2967/jnumed.115.165498.

9. Agostini D, Roule V, Nganoa C, et al. First validation of myocardial flow reserve assessed by dynamic $99 \mathrm{mTc}$-sestamibi CZT-SPECT camera: Head to head comparison with 15O-water PET and fractional flow reserve in patients with suspected coronary artery disease. The WATERDAY study. Eur J Nucl Med Mol Imaging 2018;45:1079-90. https://doi.org/10.1007/s00259-018-39 58-7.

10. Han S, Kim Y-H, Ahn J-M, et al. Feasibility of dynamic stress 201Tl/rest 99mTc-tetrofosmin single photon emission computed tomography for quantification of myocardial perfusion reserve in patients with stable coronary artery disease. Eur J Nucl Med Mol Imaging 2018;45:2173-80. https://doi.org/10.1007/s00259-018-40 57-5.

11. Ben Bouallègue F, Roubille F, Lattuca B, et al. SPECT myocardial perfusion reserve in patients with multivessel coronary disease: Correlation with angiographic findings and invasive fractional flow reserve measurements. J Nucl Med 2015;56:1712-7. https://d oi.org/10.2967/jnumed.114.143164.

12. Wells RG, Marvin B, Poirier M, et al. Optimization of SPECT measurement of myocardial blood flow with corrections for attenuation, motion, and blood binding compared with PET. J Nucl Med 2017;58:2013-9. https://doi.org/10.2967/jnumed.117.191049.

13. Zavadovsky KV, Mochula AV, Boshchenko AA, et al. Absolute myocardial blood flows derived by dynamic CZT scan vs invasive fractional flow reserve: Correlation and accuracy. J Nucl Cardiol 2019. https://doi.org/10.1007/s12350-019-01678-z.

14. Leppo JA, Meerdink DJ. Comparison of the myocardial uptake of a technetium-labeled isonitrile analogue and thallium. Circ Res 1989;65:632-9.

15. Miyagawa $M$, Nishiyama $Y$, Uetani $T$, et al. Estimation of myocardial flow reserve utilizing an ultrafast cardiac SPECT: Comparison with coronary angiography, fractional flow reserve, and the SYNTAX score. Int J Cardiol 2017;244:347-53. https://d oi.org/10.1016/j.ijcard.2017.06.012.

16. Lortie M, Beanlands RSB, Yoshinaga K, et al. Quantification of myocardial blood flow with $82 \mathrm{Rb}$ dynamic PET imaging. Eur $\mathrm{J}$ Nucl Med Mol Imaging 2007;34:1765-74. https://doi.org/10.1007/ s00259-007-0478-2.

17. Pelletier-Galarneau M, deKemp RA, Hunter CRRN, et al. Effects of hypercapnia on myocardial blood flow in healthy human subjects. J Nucl Med 2018;59:100-6. https://doi.org/10.2967/jnumed. 117.194308.

18. Pelletier-Galarneau M, Hunter CRRN, Ascah KJ, et al. Randomized trial comparing the effects of ticagrelor versus clopidogrel on myocardial perfusion in patients with coronary artery disease. $\mathrm{J}$ Am Heart Assoc 2017. https://doi.org/10.1161/JAHA.117.005894.

19. Chan SY, Brunken RC, Czernin J, et al. Comparison of maximal myocardial blood flow during adenosine infusion with that of intravenous dipyridamole in normal men. J Am Coll Cardiol 1992;20:979-85. https://doi.org/10.1016/0735-1097(92)90201-W.

20. Harel F, Finnerty V, Authier S, Pelletier-Galarneau M. Comparison of two dipyridamole infusion protocols for myocardial perfusion imaging in subjects with low likelihood of significant obstructive coronary artery disease. J Nucl Cardiol 2018;45:56-67.

Publisher's Note Springer Nature remains neutral with regard to jurisdictional claims in published maps and institutional affiliations. 